\title{
TABLES IN STATISTICAL APPENDIX
}

A- I. Percentage Distribution of California Residents by Place of Birth, Selected PAGE Census Years, 1860-r $95^{\circ}$

A- 2. Percentage Distribution of California Residents Born in Other States, by Geographic Division of Birth, Selected Census Years, 1860-1950, and for Whites and Nonwhites, 1940-1950 .

A- 3. Percentage Distribution of Increase per Decade in Number of California Residents Born in Other States, by Geographir Division of Birth, 1900r 950

A- 4. Per Cent of Population Living in Urban Areas, California and United

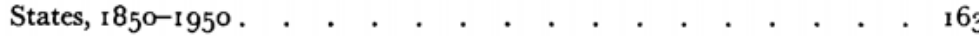

A- 5. Per Cent of Population of California Living in Southern Counties, $1850-$

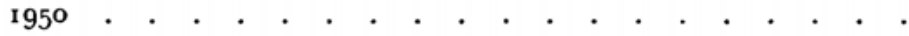

A- 6. Percentage Distribution of Net Effective Migration into California by Age Group (Estimated), 1880-1940 .

A- 7. Percentage Distribution of Population of California by Race, Selected Census Years, 1860-1950

A- 8. Number of Children under Five Years of Age per 1,ooo Population, White and Nonwhite, California and United States, 1870-1950 . . . .

A- 9. Number of Children under Five per 1,000 White Women 15 to 49 Years of Age, r850 to r950, and for Urban and Rural Women, r9ro, 1940, and 1950, California and United States.

A-1 o. Number of Children under Five per I, ooo White Women 15 to 49 Years of Age, Urban and Rural, by Age, California and United States, 1910 and 1940

A-I I. Age Distribution of the Population, California and United States, Selected Census Years, 1870-1950

A-r 2. Crude Birth Rate, California and United States, 1919-1950 . . . . 169

A-13. Gainful Workers by Major Industry Group, California and United States, 1870-1930 .

A-14. Employed Workers by Major Industry Group, California and United States, $1930-195^{\circ}$

A-15. Percentage Increase per Decade in Population and in Number of Workers by Major Industry Group, California, 1870-1950 . . . . . .

A-16. Ratio of Percentage Increase in Number of Workers to Percentage Increase in Population per Decade, by Major Industry Group, California, I870$195^{\circ}$

A-1 7. Production Workers in Manufacturing by Industry Group, California, 1899-1949. 
A-18. Percentage Distribution of Production Workers in Manufacturing by Industry Group, California, 1899-1949 . . . . . . . . . . 175

A-1 9. Percentage Distribution of Production Workers in Manufacturing by Industry Group, United States, I899-1949 . . . . . . . . . . 176

A-20. Ratio of Percentage of Manufacturing Production Workers in Each Industry Group in California to that in United States, 1899-1949 . . . 177

A-21. Percentage Increase in Number of Production Workers in Manufacturing per Decade, by Industry Group, California, 1899-1949 . . . . . 178

A-22. Ratio of Percentage Increase in Number of Production Workers in Manufacturing to Percentage Increase in Population per Decade, by Industry

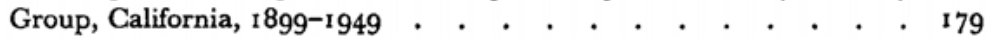

A-23. Changes in per Capita Income, California, Geographic Regions, and United States, $1919-195^{2}$. . . . . . . . . . . . . . . 180

A-24. Ratio of per Capita Income to U. S. per Capita Income, California and Geographic Regions, 1919-1952 . . . . . . . . . . . 181

A-25. Percentage Change in the Labor Force and Employment, and Fluctuations in Unemployment Rates, by Five-Year Periods, United States, 1900-1950 181 